\title{
POTENCIAL PAISAGÍSTICO NA UNIDADE DE CONSERVAÇÃO MONUMENTO NATURAL DAS ÁRVORES FOSSILIZADAS DO TOCANTINS (MONAF), MUNICÍPIO DE FILADÉLFIA (TO)
}

\author{
Carlos Augusto Machado \\ Universidade Federal do Tocantins (UFT), Curso de Geografia, Araguaína (TO) \\ delagnesse@uft.edu.br \\ Benilson Pereira de Souza \\ Inspetor de Recursos Naturais, Instituto de Natureza do Tocantins (NATURATINS), Araguaína (TO) \\ benilson.geo@homail.com
}

\begin{abstract}
RESUMO
O estado do Tocantins, em especial a região norte, preserva inúmeros sítios fósseis contendo exemplares únicos da paleovegetação em solos e rochas no ambiente dos Cerrados. Avaliar a potencialidade paisagística na Unidade de Conservação do Monumento Natural das Árvores Fossilizadas para implantação de rotas de turismo em paleoambientes com depósitos fósseis vegetais nos domínios dos Cerrados brasileiros constitui-se no foco central deste trabalho. $O$ procedimento da análise baseou-se na revisão bibliográfica de unidades de conservação de fósseis, caracterização ambiental da área, uso de imagens de satélite de escalas variadas, definição das unidades de Paisagem, trabalhos de campo para definição das possíveis locais de visitação e rotas de turismo. Através da análise pode-se constatar a degradação de fósseis por pisoteio de gado, exposição à radiação solar, umidade e microrganismos, bem como pela ação do fogo antrópico. Por meio da definição das Unidades de Paisagens elaborou-se uma rota turística que contemplasse as diversas belezas cênicas, sítios fósseis e arqueológicos e a implantação de esportes radicais. Medidas urgentes são necessárias para a conservação e preservação dos fósseis, tais como: isolamento da área, aumento da fiscalização, combate a erosão e as queimadas.
\end{abstract}

Palavras-chave: Degradação. Fósseis. Rota Turística. Monumento Natural. Estado do Tocantins

\section{LANDSCAPE POTENTIAL IN THE CONSERVATION UNIT NATURAL MONUMENT OF FOSSILIZED TREES OF TOCANTINS (MONAF), FILADÉLFIA CITY (TO)}

\begin{abstract}
The Tocantins state, in special the north region, preserves innumerous fossils sites containing only ones copies of paleovegetables in soils and stones of Cerrados environment. Evaluate the potential landscape in the Conservation Unit of Natural Monument of Fossilized Trees for deployment route tourism in paleoenvironments with formation and preservation of fossil plant deposits in the areas of Brazilian Cerrados constitutes the central focus of this work. The procedure of analysis was based on literature review of fossils conservation units, environmental characterization of area, use of satellite images in variable scales, fieldwork for the definition of possible places of visitation and tourism routes. Through the analysis, we can identify the degradation of fossil by cattle trampling, exposure to solar radiation, humidity and microorganisms, as well as by anthropic fire. By the defining of Landscape Units it can be elaborate a tourist route that contemplate the various scenic beauty, fossil and archaeological sites and radical sports. Urgent measures are necessary for the conservation and preservation of fossils, such as isolation of the area, increase of surveillance, combat of erosion and fires.
\end{abstract}

Key-words: Degradation. Fossils. Touristic Route. Natural Monument. Tocantins State

\section{INTRODUÇÃO}

A história natural pretérita de uma região encontra-se documentada nas estruturas geológicas criadas pela interação dos diversos elementos do sistema ambiental, seja nas rochas ou no gelo. Por meio destes registros é possível aferir sobre os eventos importantes que aconteceram no passado distante e esboçar o quadro de evolução futura. Os indícios dos fenômenos naturais são gravados $\begin{array}{llllll}\text { Caminhos de Geografia } & \text { Uberlândia - MG } & \text { v. 19, n. 68 } & \text { Dez/2018 } & \text { p. 250-265 Página } 250\end{array}$ 
principalmente nos depósitos sedimentares na forma deposicional ou de vestígios fósseis, os quais atestam o tipo de fauna e flora existentes, bem como as variações climáticas de um determinado ambiente.

$\mathrm{Na}$ região norte do estado do Tocantins, mais precisamente no distrito de Bielândia, município de Filadélfia, foi criada a Unidade de Conservação Monumento Natural das Árvores Fossilizadas do Tocantins, vide Figura 1, onde encontram-se litologias que preservaram os fósseis em ótimo estado de plantas entre 250 e 290 milhões de anos passados e os registros das variações climáticas ambientais mundiais que contribuíram para o desenvolvimento do bioma Cerrado, o qual domina toda a região central do Brasil. Além dos vários sítios paleontológicos na área de estudo encontram-se sítios arqueológicos com gravuras rupestres da presença humana na região que podem ser incluídos nos trajetos de visitação para o turismo.

Figura 1: Município de Filadélfia no Estado do Tocantins

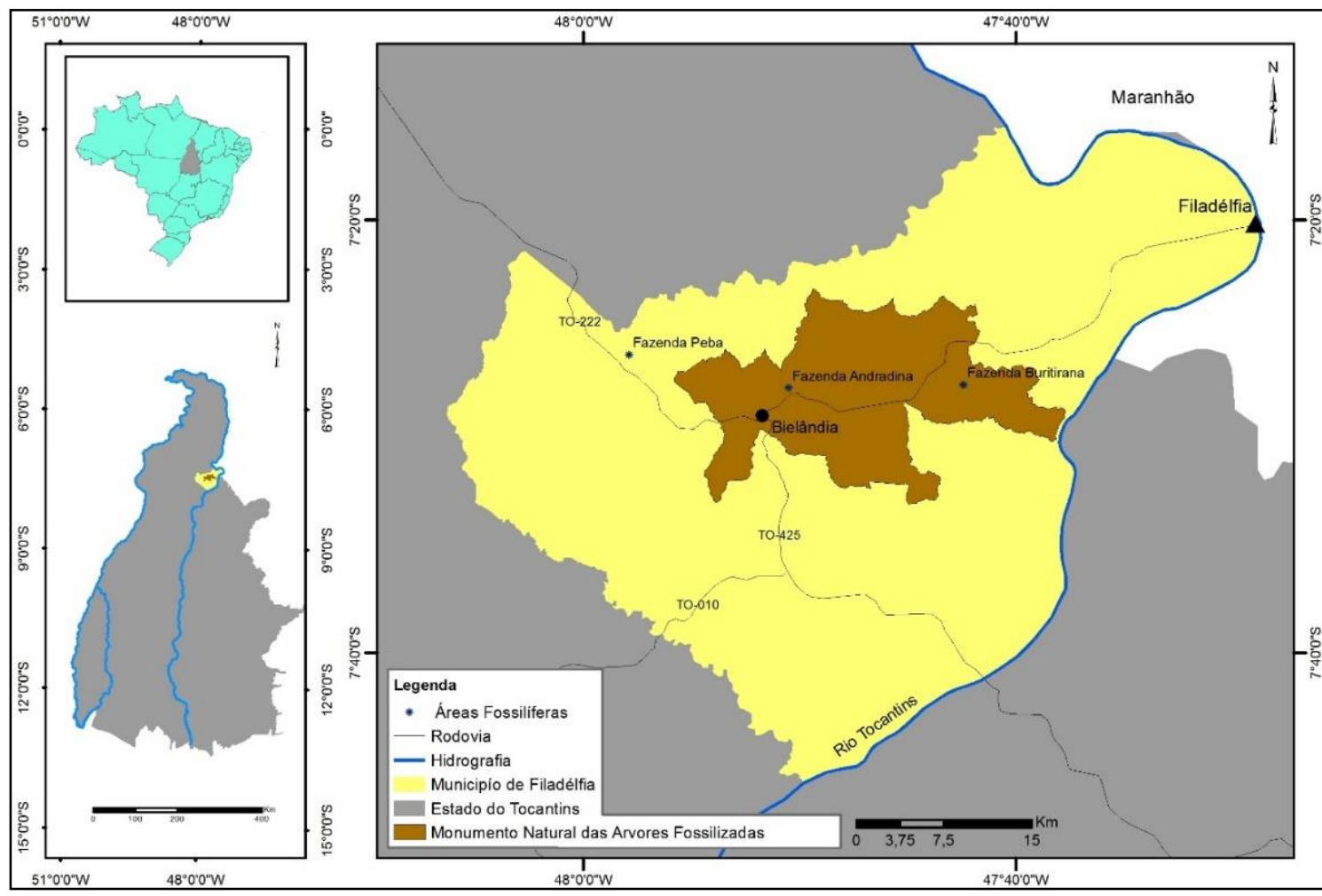

Fonte: Tocantins (2005)

Arte e Delimitação: Autores (2017)

Existe somente outra floresta de árvores fossilizadas com grande quantidade de materiais para estudo localizada no estado do Rio Grande do Sul e sítios menores de vegetais fósseis são encontrados em outras partes do Brasil, porém de pouca expressão espacial.

Constitui-se o foco central deste estudo avaliar a potencialidade paisagística para implantação de rotas de turismo em paleoambientes com formação e preservação dos depósitos fósseis vegetais na Unidade de Conservação do Monumento Natural das Árvores Fossilizadas do Tocantins nos domínios dos Cerrados brasileiros.

As rotas turísticas constituem-se em um exemplo em que é possível aliar a conservação e preservação de paleoambientes com a exploração turística, de modo a converter as áreas em possibilidades de autogestão econômica para o estado, disseminação da educação ambiental e ampliar a oferta de renda para populações local.

Os pequenos e médios proprietários e possuidores rurais, inseridos no contexto do MONAF podem ter suas rendas ampliadas com a implantação do turismo que enquadre o entendimento das diversas

$\begin{array}{llllll}\text { Caminhos de Geografia } & \text { Uberlândia - MG } & \text { v. 19, n. } 68 & \text { Dez/2018 } & \text { p. 250-265 } & \text { Página } 251\end{array}$


paisagens morros testemunhos, formações ferruginosas e calcárias, cavernas, pediplanos e sítios fósseis, bem como os recentes achados arqueológicos de inscrições rupestres e materiais líticos.

Os efeitos negativos da presença humana sobre os ambientes que contém fósseis vegetais e animais nos Cerrados tocantinenses processam-se de forma direta e indireta, necessitando de ações fortes e decisivas dos órgãos ambientais e políticas públicas voltadas à preservação do patrimônio natural.

\section{FUNDAMENTAÇÃO TEÓRICA}

Para fundamentar e delimitar a área do MONAF, Robrahn-Gonzáles et al (2002) analisaram os mais significativos sítios fósseis do município de Filadélfia apontando quais as medidas a serem tomadas quando da instalação do Monumento. Dentre os inúmeros fósseis estudados, a equipe apontou a abundante existência de pteridófitas, estenófitas, pteridospermas e as cordaitaleanas em excelente estado de conservação, demonstrando que nesta área predomina um ambiente aquático pantanoso, o qual favorecia o desenvolvimento de espécies pretéritas de palmeiras.

Segundo Robrahn-Gonzáles et al (Op cit) os sedimentos da Formação Pedra de Fogo abrigam restos de uma série de outros grupos de organismos que não foram ainda estudados em detalhe como peixes, anfíbios, bivalves, conchostráceos, ostracodes e organismos estromatolíticos.

O estudo de Tocantins (2005) elaborou o Plano de Manejo do Monumento Natural das Árvores Fossilizadas, constituindo-se em um amplo levantamento das características naturais e a análise detalhada dos parâmetros a serem seguidos na gestão da unidade, abrangendo não somente os aspectos ambientais, mas também fatores sócio-econômicos e culturais da região onde se localizam os sítios fósseis.

De acordo com a clássica definição de Bertrand (1972), deve-se entender que:

A paisagem não é a simples adição de elementos geográficos disparatados. É, em uma determinada porção do espaço, o resultado da combinação dinâmica, portanto instável, de elementos físicos, biológicos e antrópicos que, reagindo dialeticamente uns sobre os outros, fazem da paisagem um conjunto único e indissociável, em perpétua evolução. A dialética tipo-indivíduo é próprio fundamento do método de pesquisa (Bertrand, 1972, p. 141).

Portanto, qualquer análise que não leve em conta a evolução constante da Paisagem sob o ponto de vista antrópico e ambiental estará engessando a possibilidade de entendimento da situação. A classificação de Paisagens deve ser pontuada em fatores que sejam essenciais ao determinado tipo de estudo que se propõem a fazer sem perder a visão holística.

Segundo Konold (2007) no entendimento da dinâmica das Paisagens é necessário que:

Changes in the cultural landscapes has speeded up considerably in the last decades, accompanied by a dramatic increase in developed and especially covered areas and the well-known negative effects on habitats, flora and fauna and on the geomorphology. Individual facial features of the cultural landscapes, their value and character were often obliterated or removed (Konold, 2007, p. 18).

Mudanças nas paisagens culturais aceleram-se consideravelmente nas últimas décadas, acompanhado por um dramático aumento no desenvolvimento $e$ especialmente coberto áreas e efeitos negativos bem conhecidos no habitat, flora e fauna e na geomorfologia. Características faciais individuais de paisagens culturais, seu valor e caráter foram obliterados ou removidos (Konold, 2007, p. 18).

A opção deste trabalho em definir as unidades de paisagem a partir de critérios geológicos e geomorfológicos como base para as ações humana e suas atividades econômicas, culturais e sociais é reforçada por Vieira; Cunha (2002) destacando que:

Os elementos geomorfológicos constituem a base sobre a qual se desenvolve a paisagem, condicionam o coberto vegetal e muitas actividades humanas, resultando assim como factor estruturante das diversas paisagens, razão pela qual 
frequentemente se fala de paisagem de montanha, paisagem litoral, paisagem granítica, paisagem cársica, etc...Podemos entender, também, o conjunto das formas de relevo como componentes do sistema ambiental que, pela sua originalidade, singularidade e raridade e, mesmo, como é o caso das paisagens de montanha, dotar a paisagem de características e dinâmicas muito próprias que lhe conferem um cunho articular e uma identidade própria. (Vieira; Cunha, 2002, p. 02).

Oliveira (2005) destaca a evolução de técnicas palinológicas em análise de registros sedimentares, as quais favoreceram a compreensão do complexo padrão das diferentes formações vegetais brasileiras, aliando ao estudo dos fósseis vegetais para a reconstrução da vegetação em diferentes épocas geológicas no território brasileiro. Estudos desta natureza contribuem para o entendimento da evolução fitofisionômica do bioma Cerrados, uma vez que assentado sobre o centro do território brasileiro sofre influência de outros biomas que circundam sua área e que respondem rapidamente as flutuações climáticas com expansão ou retração de suas áreas.

Brilha (2005) em seu trabalho destaca a importância dos levantamentos e estudos do patrimônio geológico e geomorfológico para a criação de Geoparques visando a exploração da atividade turística em Portugal e na Europa. Devido ao enorme peso na economia dos ganhos com a atividade turística, o autor aponta que são necessárias estratégias de geoconservação que envolvam a quantificação de áreas, classificação quanto à possibilidade de uso, valorização e divulgação, monitoramento e estratégias de geoconservação baseada em critérios técnicos.

Em relação ao desenvolvimento das atividades turísticas e os impactos ambientais gerados por esta atividade, Ruschmann (1997) enfatiza que:

A finalidade do planejamento turístico consiste em ordenar as ações do homem sobre o território e ocupa-se em direcionar a construção de equipamentos e facilidades de forma adequada evitando, dessa forma, os efeitos negativos nos recursos, que destroem ou reduzem sua atratividade (Ruschmann, 1997, p. 9).

Visando ampliar e diversificar as atividades econômicas de um município em que existem Unidades de Conservação (UCs), Peixe (2010, p. 7) destaca que: "O ecoturismo é uma das atividades que mais se expande nas UCs por ser considerado de baixo impacto ambiental, também por selecionar os turistas que procuram explorar esse meio beneficiando-o economicamente".

\section{METODOLOGIA}

O desenvolvimento do tema proposto neste estudo obedeceu à seguinte estrutura de análise.

Revisão bibliográfica enfocando os estudos das ações e alterações antrópicas e projetos de caráter ambiental que buscam em sua concepção a diminuição dos efeitos negativos em UCs, bem como estudos de identificação, conservação e preservação de sítios fósseis, e arqueológicos.

A caracterização e a dinâmica ambiental da área de estudo e a definição das Unidades de Paisagem baseada nos aspectos geoambientais servirá de suporte para avaliar o potencial paisagístico da unidade de conservação, bem como a criação das rotas turísticas, na qual serão utilizados os levantamentos pedológicos, hidrológicos e fitogeográficos do Projeto RADAM BRASIL (1974) e os trabalhos de Tocantins (2001 e 2004).

A realização de trabalhos de campo visa identificar e avaliar os processos de degradação dos sítios fósseis/ arqueológicos, definindo o possível aproveitamento destas áreas na atividade turística como aumento do leque de pontos históricos/ambientais de visitação na Unidade de Conservação. As rotas turísticas bem como a capacidade de carga serão definidas de acordo com os critérios enfocados por Brilha (2005), tais como: facilidade acesso às pessoas de todas faixas etárias, facilidade do trânsito de veículos e curtas distâncias de caminhadas, sítios com boa diversidade de fósseis para observação, exclusão de áreas de pesquisa e fósseis raros, limitação da quantidade de pessoas por fiscais e guardas. Além dos critérios expostos anteriormente serão incluídas as informações da experiência dos responsáveis da UC na atividade de visitação nos últimos 5 anos de algumas das 
rotas existentes e de outras rotas propostas por este estudo e avaliadas pelo Conselho Consultivo da unidade

A localização e mapeamento dos sítios fósseis contou com imagens de satélite SPOT disponíveis no software Google Earth e utilização de GPS da marca Garmim, modelo Vista HCx.

Entrevistas com a população local e profissional dos órgãos municipais e estaduais responsáveis pela Unidade de Conservação.

A Paisagem na Unidade de Conservação nas últimas décadas vem sendo alterada de forma significativa e para entender a dinâmica atual, este trabalho utilizou-se do esquema proposto por Bertrand (1972) que correlaciona o Potencial Ecológico (clima, hidrologia e geomorfologia), Exploração Biológica (vegetação, solo e fauna) e Ação Antrópica (atividades econômicas). A definição das Unidades de Paisagem teve como critério a estrutura geológica em virtude do enfoque dos fósseis preservados na Formação Pedra de Fogo. Com base neste critério foram definidas quatro unidades, a saber: Unidade de Paisagem I - Pedra de Fogo, Unidade de Paisagem II - Formação Sambaíba, Unidade de Paisagem III - Formação Motuca, Unidade de Paisagem IV - Formação Piauí, Unidade V - Formação Poti e Unidade VI - Aluviões holocênicos.

Os resultados obtidos neste estudo serão inseridos nas várias atividades desenvolvidas nos últimos anos pelo convênio firmado entre a Universidade Federal do Tocantins (UFT), campus de Araguaína e o Instituto de Natureza do Tocantins (NATURATINS) responsável pela Unidade de Conservação. O convênio destaca a realização de estudos, trabalhos de campos, apoio à visitação de alunos da rede pública no qual a UFT atua com professores e estagiários do curso de Geografia e a participação no Conselho Consultivo da Unidade de Conservação, no qual acrescenta-se a participação da Prefeitura de Filadélfia, associação de assentados e proprietários rurais, avaliando e planejando as atividades desenvolvidas dentro da área de conservação.

Análise dos dados e informações obtidas para o entendimento da situação atual para servirem de base para as propostas com base no planejamento ambiental.

\section{MONUMENTO NATURAL DAS ÁRVORES FOSSILIZADAS DO ESTADO DO TOCANTINS}

O MONAF, abriga uma das mais completas florestas fossilizadas do mundo. Esta floresta desenvolveu-se no Período Permiano da Era Paleozóica, entre 250 e 295 milhões de anos. No final deste período, nosso planeta assistiu à maior extinção em massa da fauna e flora jamais ocorrida, tendo desaparecido algo como $90 \%$ das espécies marinhas e talvez $70 \%$ das terrestres. A flora Permiana do Monumento Natural era muito distinta da atual, com predominância de pteridófitas (samambaias), coníferas e cicadáceas (cicas) segundo Robrahn-Gonzáles et al (2002).

A área onde existem os fósseis corresponde à borda do antigo lago predominando pântanos e alagados. Não existiam plantas com flores, que só apareceriam muitos milhões de anos depois.

Somente após denúncias de saques aos sítios fósseis, o governo do estado do Tocantins criou uma Unidade de Conservação denominada "Monumento Natural das Árvores Fossilizadas do Estado do Tocantins", através da Lei no 1.179 de 04 de outubro de 2000, tendo como objetivo proteger e conservar as diversidades biológicas e paleontológicas existentes no local.

A área do Monumento das Árvores Fossilizadas é composta pelas seguintes formações geológicas, a saber: Formação Sambaíba de origem eólica, Formação Pedra de Fogo de origem marinha, Formação Motuca de origem marinha, Coberturas Detrítico Lateríticas e Depósitos aluvionares do rio Tocantins.

A parte superior do pacote litológico é composto pela Formação Sambaíba, de origem eólica, com destaque para o relevo de chapadas e morros testemunhos, o qual confere beleza significativa ao ambiente local e de refúgio para inúmeras espécies da fauna, além de possuir sítios arqueológicos que atestam a presença humana, porém pouco estudados.

Neste pacote sedimentar não ocorrem registros de fósseis que possam atestar a evolução paleobiogeográfica da área, somente na faixa de contato entre a formação Pedra de Fogo e Sambaíba, os quais se encontram encravados em coberturas detrítico lateríticas, revestindo os fósseis com óxidos de ferro, abundantes nesta unidade (Brasil, 2001).

Apesar de vestígios fósseis serem encontrados nas áreas de contato das formações geológicas anteriormente citadas, é na Formação Pedra de Fogo que se localizam inúmeros depósitos de fósseis

\begin{tabular}{llllll}
\hline Caminhos de Geografia & Uberlândia - MG & v. 19, n. 68 & Dez/2018 & p. 250-265 & Página 254
\end{tabular}


de vegetais em grandes quantidades que se encontram expostos pela ação erosiva natural e aceleradas pela ação antrópica. A área da Formação Pedra de Fogo é composta de rochas sedimentares marinhas de grande extensão territorial nos estados do Tocantins, Maranhão e Piauí, vide Figura 2 e que preservou principalmente fósseis de árvores de ambiente aquático e esqueletos de peixes. Segundo Santos; Carvalho (2004) a madeira fóssil Psauronius brasiliensis foi coletada entre 1817 e 1920 pelo botânico Martius e descrita por Brongniart em 1827, sendo o primeiro fóssil vegetal do Brasil a ser mencionado na literatura.

Figura 2: Formação Pedra de Fogo no Brasil

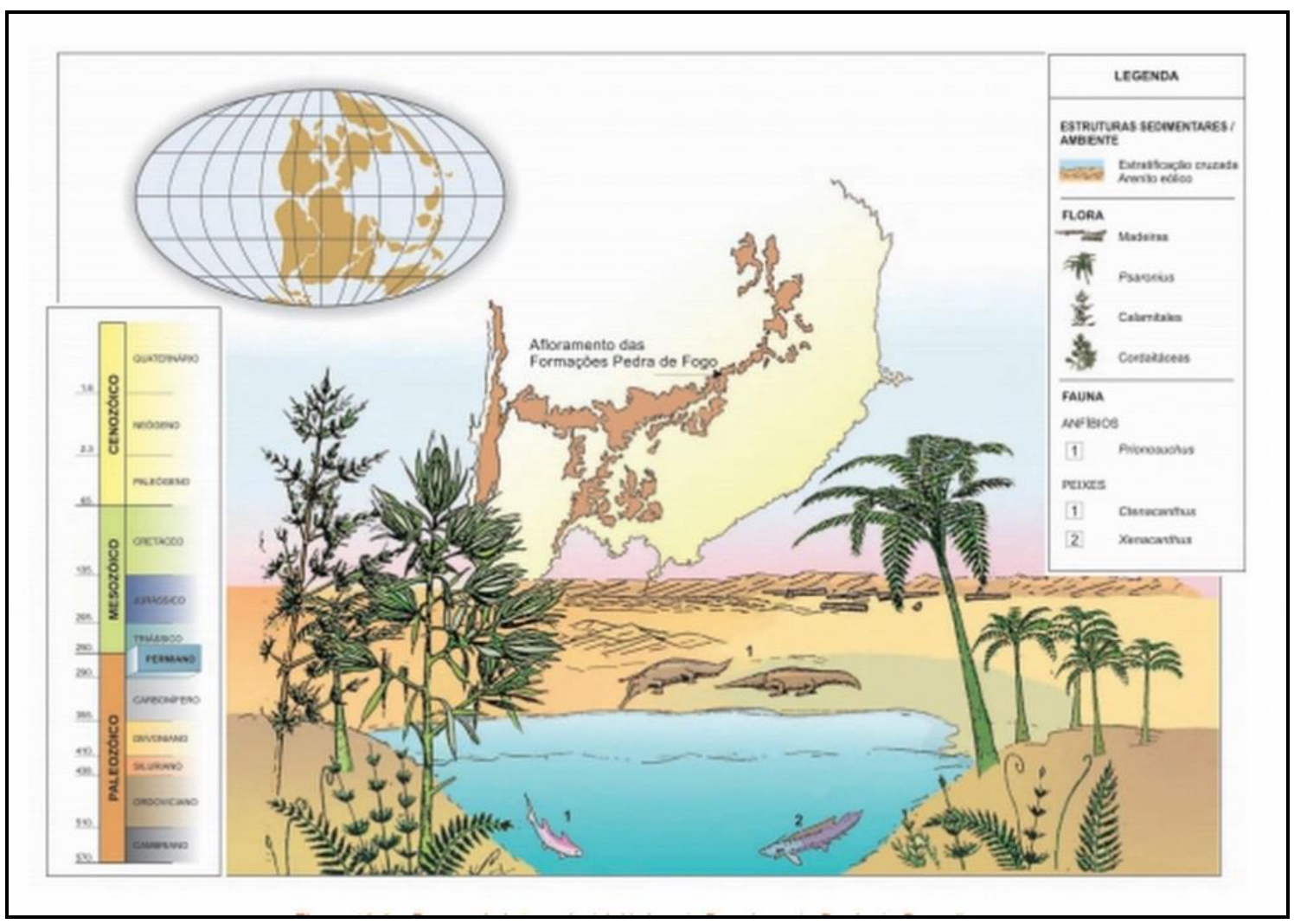

Fonte: Santos; Carvalho (2004)

O levantamento científico para mapeamento e identificação de fósseis vegetais requisitado pelo governo estadual aprofundou o conhecimento da paleoflora e gravuras rupestres, mais ficou circunscrito as maiores áreas de material fóssil, sendo a identificação e mapeamento dos pequenos sítios pouco explorados ou mesmo a descoberta de novos locais relegada a estudos posteriores. Outro aspecto pouco estudado nos relatórios que seguiram diz respeito sobre a distribuição espacial das espécies vegetais na área, bem como a evolução e dinâmica do ambiente de formação dos fósseis, principalmente no estudo dos depósitos fósseis sedimentares que atestam a transição de um clima úmido a um quente, típico de deserto na transição das Formações Pedra de Fogo e Motuca.

\section{ESTRUTURA FÍSICA DO MONAF E DO DISTRITO DE BIELÂNDIA}

A sede do MONAF encontra-se no distrito de Bielândia, localizado no entroncamento das rodovias estaduais TO - 222 e TO- 425, a $50 \mathrm{~km}$ da sede do município de Filadélfia. O povoado conta com aproximadamente 725 moradores segundo dados do cadastro dos agentes comunitários de saúde, dotado de pouca infraestrutura, com somente uma pequena escola, um posto de gasolina, pequenos restaurantes, nenhum hotel ou pousada, sendo economicamente dependente das pessoas que trabalham em fazendas da região e do pequeno comércio local. Somente duas empresas de ônibus atendem o distrito diariamente. 
A estrada estadual (TO-222) que corta a UC margeia a maior parte dos afloramentos fossilíferos resultante do aparecimento de ravinas causadas pelo deslocamento do gado. Inúmeros outros depósitos foram parcialmente expostos, mas localizados na parte interna do MONAF com difícil acesso.

Em praticamente todas as fazendas situadas na UC existe rede elétrica e água de boa qualidade retirada de poços rasos e cursos de água. Somente na Formação Pedra de Fogo de origem marinha (Unidade Ambiental II) a água é levemente salobra, sendo necessária a perfuração de poços mais profundos.

O quadro de funcionários do MONAF é composto por um Supervisor, Inspetores, Guarda-Parques, Assistentes Administrativos, motoristas e auxiliar de serviços gerais. As ações de fiscalização na unidade são feitas por Guarda-Parques e inspetores, quando necessário, tem o apoio da Agencia Regional do Naturatins de Araguaína e da Polícia Militar Ambiental.

A infraestrutura de visitação e de pesquisa é composta por um Centro de Recepção de Visitantes, museu, contendo sede administrativa, alojamentos, auditório, área de socialização e garagem, além de veículos para fiscalização.

As sedes de fazenda são na sua maioria de alvenaria e possuem capacidade de serem adaptadas para receber visitantes temporários ou que pernoitem dependendo do investimento e quantidade de pessoas. Deve-se salientar que é extremamente necessário um projeto de capacitação com os possíveis parceiros locais para a implantação de rotas de turismo.

\section{CARACTERIZAÇÃO E DINÂMICA AMBIENTAL DAS UNIDADES DE PAISAGEM}

A área de estudo dividida em quatro unidades ambientais, vide Figura 3, baseadas na estrutura geológica confere características diferenciadoras de aspectos geomorfológicos, pedológicos, fitogeográficos e hidrológicos de cada área em conjunto com a dinâmica climática, demonstram o Potencial Ecológico atuando em consonância com a Exploração Biológica e a Ação Antrópica.

Figura 3: Unidades de Paisagem do MONAF

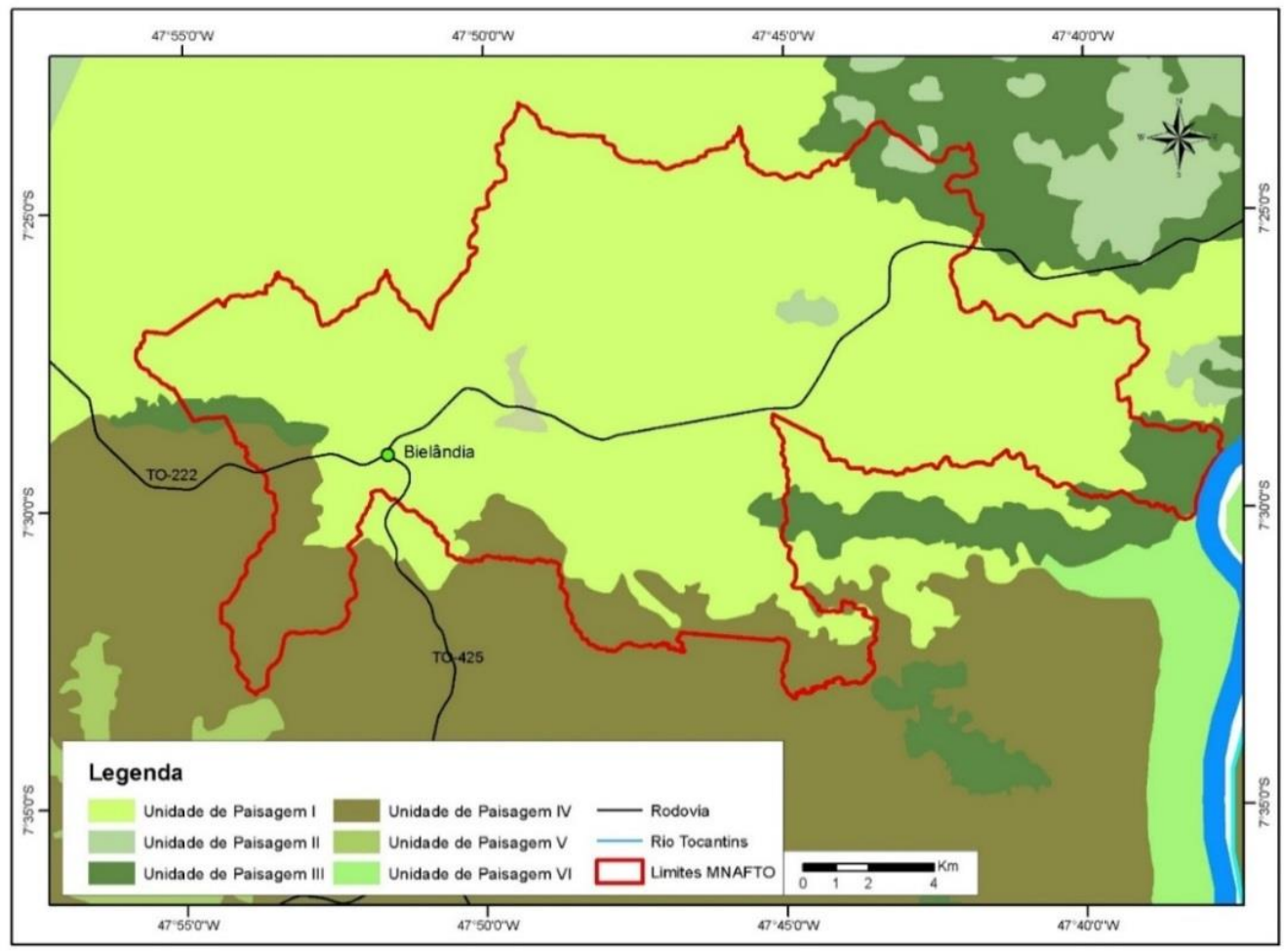

Fonte: Tocantins (2005)

Arte e Delimitação das Unidades: Autores (2017) 
A Unidade de Paisagem I é composta pelos depósitos sedimentares da Formação Pedra de Fogo, de origem marinha, atesta a regressão marinha acontecida em toda a bacia hidrográfica do rio Parnaíba. Tal depósito é constituído de sedimentos argilosos de coloração extremamente variada (rosa-cinzaverde). De acordo com Brasil (2001) esta formação possui siltitos carbonáticos cinza-esverdeados, com intercalações de calcários, arenitos fossilífero, folhelhos, conglomerados, silexitos e gipsita. Conglomerados polimíticos com interdigitações de siltitos, folhelhos e silexito (Fácies Rio das Barreiras-rb).

$\mathrm{Na}$ Unidade I, os solos argilosos e siltosos como os Argilosolos e Plintossolos apresentam pouca profundidade (1-2 metros) e com a existência de muita pedregosidade, fato este que dificulta qualquer tipo de atividade agrícola de subsistência ou mecanizada. A área apresenta baixo Potencial Ecológico e de Exploração Biológica, tendo como exemplo, a atividade pecuária que é predominante sendo afetada pelas condições pedológicas (solos distróficos) somados à natureza argilosa e as camadas concrecionárias que armazenam pouca água, fato este que restringe o crescimento e manutenção das gramíneas no período de estiagem que se estende de maio à outubro promovendo o ressecamento e grande propensão as queimadas que são constantes neste período. A atividade agrícola devido à pobreza mineral e grande pedregosidade restringe-se a pequenas áreas de cultivos de subsistência localizadas nas várzeas dos rios onde a fertilidade apresenta melhores condições.

Os recursos hídricos são afetados enormemente pela estiagem com o volume de água nos cursos de água estando completamente seco, já que na área da UC, além de afetar o volume e a qualidade da água das inúmeras represas das fazendas que servem para a dessedentação dos animais.

A Unidade de Paisagem II é composta por arenitos eólicos da Formação Sambaíba, pertencentes à Bacia do Parnaíba. Estas rochas sedimentares formaram-se no período Triássico entre 220 e 200 milhões de anos passados, a qual se constitui de arenitos médios à finos com estratificações cruzada e acanalada de grande a médio porte, localmente aparecem arenitos finos com estratificação cruzada tangencial e alguns locais estratificação planar Tocantins (2004) e Brasil (2001).

Nesta unidade, os arenitos apresentam camadas silicosas e lateríticas que esculpidas pela ação pluvial resultaram em relevos testemunhos e extensas chapadas de extrema beleza. Em outras áreas desta unidade, os arenitos apresentam a formação de um relevo de colinas amplas e de baixa topografia variando entre 275 a 300 metros, suavemente onduladas com inclinação média de $7 \%$ a $15 \%$, somente sendo identificadas inclinações mais incisivas nas cabeceiras de drenagem e próximo aos fundos de vale.

Destacam-se grandes extensões de camadas lateríticas com espessura de até 1,5 metros em alguns pontos na parte central do MONAF entre o contato da Formação Pedra de Fogo com a Formação Sambaíba atestando a mudança climática de ambiente úmido para desértico

Predominam nesta unidade os Neossolos quartzarênicos nas áreas planas intensamente lixiviados, profundos, bem drenados e com forte atuação dos processos erosivos superficiais e ravinares e Neossolos litólicos em áreas inclinadas junto aos relevos testemunhos.

A Unidade de Paisagem III é composta pelos arenitos da Formação Motuca estruturada no período Permiano e pertencente à Bacia Sedimentar do Parnaíba. Esta formação apresenta rochas sedimentares de origem marinha com estratificação cruzada e intercalações de argilitos e siltitos com sua gênese datada entre 230 e 220 m.a. resultante de transgressões marinhas na bacia do rio Parnaíba de acordo com Tocantins (2004) e Brasil (2001).

Devido à composição arenosa das rochas Formação Motuca, a pedogênese gerou solos friáveis do tipo Neossolo quartzarênico, com baixo teor de matéria orgânica, grande percentual de areia fina, bem drenados e de boa permeabilidade e porosidade e com mais de 6 metros de profundidade de acordo com Menk et al (2004). Nos fundos de vale encontram-se Gleysolos minerais e a formação de Neossolos flúvicos de formação recente em virtude da grande deposição de sedimentos na calha fluvial. Os arenitos desta unidade apresentam um relevo de colinas amplas e de baixa topografia com cotas de 200 a 250 metros, suavemente onduladas com inclinação média de $7 \%$ a 10\%, somente sendo identificadas inclinações mais incisivas nas cabeceiras de drenagem, segundo Tocantins (2004).

A textura arenosa facilita a lixiviação e a instalação de processos erosivos com a retirada da cobertura vegetal dos Cerrados diminuindo o Potencial Ecológico e a Exploração Biológica, já inexistente na área, a qual era anteriormente composta por árvores de pequeno porte, espaçadas, galhos retorcidos, cascas grossas e com raízes profundas. De acordo com Tocantins (2004) a

$\begin{array}{llllll}\text { Caminhos de Geografia } & \text { Uberlândia - MG } & \text { v. 19, n. 68 } & \text { Dez/2018 } & \text { p. 250-265 Página } 257\end{array}$


pluviosidade anual apresenta totais entre 1.400 e $1.700 \mathrm{~mm}$ com duas estações bem definidas, uma chuvosa e quente e outra seca e quente. No período entre os meses de janeiro e abril, os totais mensais variam entre 250 e $300 \mathrm{~mm}$ com chuvas intensas favorecem a morfogênese em detrimento da pedogênese, sendo comuns nesta unidade os processos erosivos ravinares.

A Formação Piauí compõe a Unidade de Paisagem IV sendo caracterizada para designar as camadas carboníferas do Pensilvaniano, compostas por arenitos finos à grossos, bimodais, de cores vermelha, cinza e amareladas, normalmente friáveis, com estratificação cruzada tangencial de médio porte com intercalações de siltitos, argilitos e folhelhos vermelhos e arroxeados e calcários calcíticos e dolomiticos segundo Tocantins (2004).

Esta unidade é composta por Chernossolos que apresentam uma profundidade média de 2 metros, eutróficos, pouca pedregosidade e uma relevo suave ondulado que facilita a atividade pecuária, sendo apenas restringida pela estação de estiagem que compromete o desenvolvimento das gramíneas. Os recursos hídricos nesta unidade apresentam mais protegidos em função da inexistência de processos erosivos devido à grande quantidade da área de reservas legais e as matas ciliares.

A Formação Poti que compõe a Unidade $\mathrm{V}$ aflora na área sul de amortecimento do Monumento Natural e compõe-se de arenitos róseos à esbranquiçados, de granulação fina à grossa conglomeráticos e micáeos com camadas de siltitos e folhelhos predominado no topo (Tocantins, 2004).

$\mathrm{Na}$ área oeste do Monumento junto ao rio Tocantins a Unidade VI é composta de Aluviões holocênicos com sedimentos inconsolidados de areia, material siltico-argiloso e cascalho. Esta unidade apresenta solos pobres, vegetação de cerrado campestre e um relevo plano.

A vegetação dos Cerrados na área do MONAF possui uma diversidade de subtipos, em função do ambiente variável de solos distróficos e eutróficos e relevos de chapadões e extensos pediplanos, variando do campo sujo ao Cerradão. Em fundos de vale predominam os Buritizais e em área com forte atividade antrópica o domínio dos Babaçuais, possuindo extensas áreas que favorecem a manutenção da fauna local.

A paleoflora existente na área está exposta aos impactos das atividades antrópicas, as quais foram iniciadas na década de 1950, através de colonos provenientes dos estados do Maranhão e Piauí, ampliadas após a construção da rodovia Belém-Brasília (BR-153). A atividade econômica predominante desde a época da ocupação até os dias atuais é a pecuária extensiva, de pouca expressão tecnológica e biológica, resultante do baixo emprego de capital e do ambiente de solos distróficos, de textura arenosa e uma prolongada estação seca entre os meses de maio e outubro.

A dinâmica antrópica de ocupação da área baseou-se no método arcaico de desmatamentos e queimadas para implantação das pastagens artificiais sem manutenção da fertilidade dos solos, fatores estes que favoreceram a exposição dos solos a processos erosivos e exumação de sítios fósseis. As queimadas em especial são muito comuns na prática de manejo do solo na área, danificando sensivelmente a camada pedológica.

Em conjunto com a diminuição e alteração da composição faunística e florística dos biomas no Brasil Central, principalmente os Cerrados, esta área está associada a um passado geológico e climatológico de formações sedimentares eólicas de aproximadamente 200 milhões anos (Brasil, 2001).

Tais formações deram origem a uma cobertura pedológica constituída por Neossolos Quartzarênicos e Latossolos Amarelos recobrindo grandes extensões, os quais são extremamente susceptíveis aos processos erosivos e de arenização, alguns exemplos de formação destes areais de ordem natural podem ser identificados mais expressivamente na região do Jalapão, estado do Tocantins, conhecida por suas dunas resultantes do retrabalhamento dos depósitos geológicos e cobertura pedológica.

A fragilidade do material que recobre os fósseis acaba facilitando sua exposição, que se encontram na camada inferior de caráter areno/argiloso. Devido ao impacto e o grande volume das fortes pluviosidades que ocorrem no período de verão, formam-se erosões que evoluem de ravinas para voçorocas com o consequente deslocamento e fragmentação dos fósseis vertente abaixo.

A problemática da fragilidade dos solos sob a perspectiva da arenização e savanização foi descrita em trabalhos do geógrafo Ab'Saber (1977), destacando a ação antrópica acentuando o processo de degradação ambiental em algumas áreas, citando os estados do Tocantins e Maranhão sujeitas a 
esta situação, principalmente na bacia do rio Tocantins. Em algumas regiões do estado do Tocantins, os processos de desmatamentos e queimadas acabam por provocar o surgimento de areais, ou seja, pequenas manchas de solo extremamente arenoso totalmente desprovido de vegetação que facilitam a erosão e diminui as áreas possíveis para atividades econômicas.

O fogo de origem natural provocado por raios é necessário para o ciclo biológico de várias plantas pirofíticas dos Cerrados segundo Rizzinil (1997), este, porém geralmente precede as chuvas que limitam sua atividade destrutiva a outras plantas. No caso do fogo antrópico, a queima dos pastos para a renovação da pastagem, geralmente ampliadas pela intensidade dos ventos e a baixa umidade do ar, como no caso da área central do Brasil, acaba pulverizando enormes áreas de vegetação.

A cobertura vegetal dos Cerrados por situar-se no centro do país possui várias áreas de transição fitofisionômica, constituindo-se num mosaico de espécies extremamente variante em pequenas porções do território, dificultando a sua identificação e principalmente sua recuperação em caso de degradação, visto que este quadro é resultante das transformações paleogeográficas iniciadas há 18 mil anos passados (Ab'Saber, 2003).

Devido à extensa área da Unidade de Conservação e sua área de amortecimento, o Instituto de Natureza do Tocantins (NATURATINS), órgão responsável pela gestão da unidade, diligencia periódicas rotas de fiscalização e ações de educação ambiental. Nas décadas passadas toneladas de material fóssil foram roubados e vendidos principalmente para o exterior, deixando os sítios incompletos para estudos posteriores.

\section{MAPEAMENTO E DEFINIÇÃO DAS ROTAS TURÍSTICAS}

A área do MONAF e seu entorno oferecem várias possibilidades de rotas de turismo, vide Figura 4, que podem ser temáticas ou diversificadas conforme o grupo de pessoas que podem visitar a área, sendo possível a adaptação conforme a necessidade. Deve-se salientar que rotas de difícil acesso, áreas com fósseis raros, terrenos inclinados, estradas sem conservação, período de chuvas intensas (Dezembro-Maio) ou que a visitação provoque impactos no ambiente pela fragilidade e capacidade de carga foram excluídos deste estudo de acordo com critérios estabelecidos por Brilha (2005).

Deve-se ressaltar que em Unidades de Conservação, o Decreto $n^{0} 4.340$, de 22 de agosto de 2002, que regulamenta artigos da lei $n^{\circ}$ 9.985, de 18 de julho de 2000 e que dispõe sobre o Sistema Nacional de Unidades de Conservação da Natureza (SNUC), as atividades dentro destas áreas necessitam de autorização do órgão competente exposto em BRASIL (2011).

$\mathrm{Na}$ questão das rotas turísticas, a visitação é limitada pela sazonalidade climática, pois no período chuvoso, o terreno devido à natureza argilosa e siltosa dos solos tornam-se escorregadios dificultando o acesso e facilitando acidentes mesmo em declividades suaves. Devido também o calor no período de estiagem, a escolha de trilhas com curta distância e o deslocamento a pé não provocará fadiga nos visitantes. Em todos os locais escolhidos para as rotas não se apresenta problemas ambientais como erosões, assoreamento dos rios, fontes de poluição hídricas, somente em alguns casos na época de estiagem podem ocorrer queimadas, sendo a visitação suspensa para o combate ao fogo.

O grande atrativo das rotas deve-se centralizar nos sítios fósseis que conferem a importância da área e como alguns locais próximos à rodovia TO-222 já foram bem estudados podem se tornar espaços de fácil visitação e com infraestrutura adequada.

No caso desta proposta de rota turística no MONAF optou-se por diversificar os pontos de interesse e não setorizar por temas proporcionando assim uma melhor compreensão dos vários temas das diversas Paisagens que compõem a área da unidade de conservação. Deste modo, optou-se por iniciar a rota pelo motivo de formação da Unidade de Conservação, ou seja, os sítios fósseis e que encontram-se próximos as rodovias que cortam o Unidade, em seguida definiu-se como pontos de paradas as áreas de belezas cênicas (relevos testemunhos, chapadas e palmeirais), no momento seguinte seriam observados áreas de matas e suas características florísticas e pequenos trechos de caminhadas para observação das estruturas geomorfológicas e sítios arqueológicos, restando para o último momento os pontos onde se encontram as cachoeiras e cursos de água passíveis de lazer e esportes de aventura. 
As duas áreas mais importantes com sítios fósseis localizam-se na fazenda Andradina e Fazenda Buritirama, vide Figura 4 e 5, que apresentam grande diversidade de fósseis vegetais e grandes quantidades de materiais que já produziram inúmeros estudos sobre o tema. De acordo com os critérios de Brilha (2005) para seleção de rotas e capacidade de visitação, as duas áreas possuem acesso fácil, com ampla área de visitação, curta distância de deslocamento das pessoas, acessível para todas as faixas etárias, estradas em bom estado para os veículos e sítios localizados em terrenos planos.

O tempo gasto em média para a visitação é de 1:00 à 1:30 h nos fósseis e 1 hora na sede para apresentação da Unidade de Conservação definido pela experiência com a visitação e da palestra de explicação da formação dos fósseis pelos responsáveis pela unidade e que atualmente é de 3 técnicos para cada 10 visitantes, sendo um guia e dois inspetores ambientais. Apesar da possibilidade de uma maior quantidade de visitação diária, os responsáveis fixaram em uma visita pela manhã e outra pela tarde evitando a sobrecarga do trânsito de pessoas no ambiente.

Infelizmente devido ao pouco investimento do governo na instalação de equipamentos adequados a visitação (pequenas passarelas, sinalização, entre outros) e dos proprietários, os sítios estão expostos às intempéries e a saques do material.

Figura 4: Rota Turística no interior e Zona de Amortecimento do MONAF

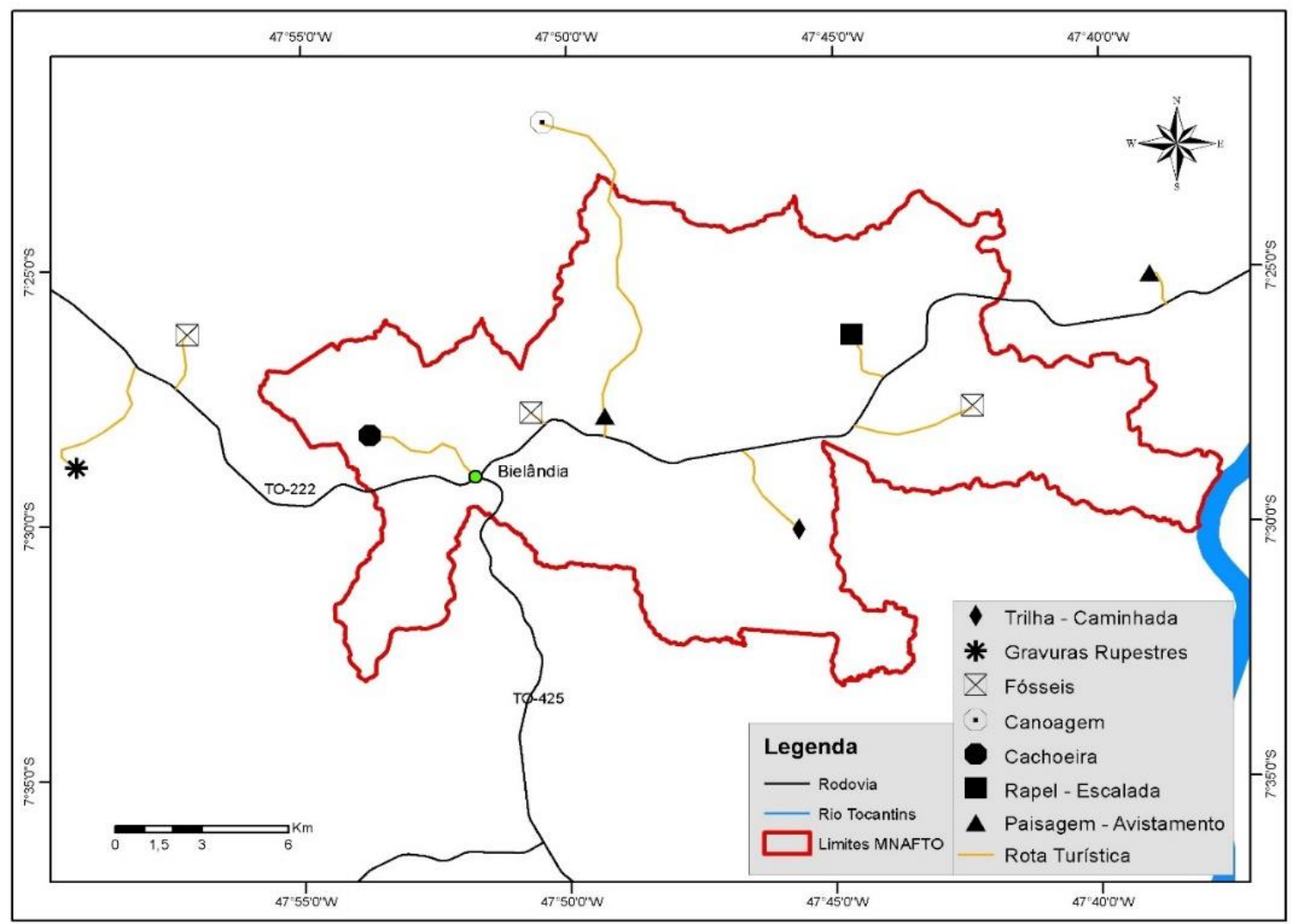

Fonte: Tocantins (2005)

Arte e estruturação: Autores (2017)

A Formação Pedra de Fogo na região leste do estado do Tocantins apresenta somente fósseis vegetais, vide Figura 5, inexistindo fósseis animais ou íctios nesta área, porém, afloramentos desta litologia na região central do estado apresentam fósseis de conchas, peixes e dentes de tubarões. No estado do Maranhão foram identificados fósseis de animais, fatos estes corroboram a necessidade de mais estudos para o entendimento e determinação da paleobiogeografia e dos paleoambientes (Santos; Carvalho, 2004).

Outro destaque no MONAF são as estruturas geomorfológicas (relevos testemunhos), vide Figura 6 , que apresentam grande beleza cênica que podem ser agregados às paradas para refeições e

$\begin{array}{llllll}\text { Caminhos de Geografia } & \text { Uberlândia - MG } & \text { v. 19, n. 68 } & \text { Dez/2018 } & \text { p. 250-265 } & \text { Página } 260\end{array}$


descanso. Em alguns locais e horas definidas, além da beleza cênica das estruturas areníticas somam-se locais com cachoeiras para banho e no horário vespertino podem ser observados inúmeros tipos de pássaros nos paredões dos relevos testemunhos se recolhendo em seus ninhos escavados na rocha.

Estas rotas enquadram-se nos mesmos critérios avaliados para os fósseis anteriormente discutidos, com facilidade de acesso as diferentes faixas etárias, trilhas adequadas, ampla área de observação, relevo plano e que respeita a quantidade de 30 pessoas para os 3 técnicos responsáveis, salientando que ainda faltam placas com informações, as quais já foram elaboradas e enviadas para o governo do estado para aquisição.

Figura 5: Fósseis Expostos pela Erosão Pluvial

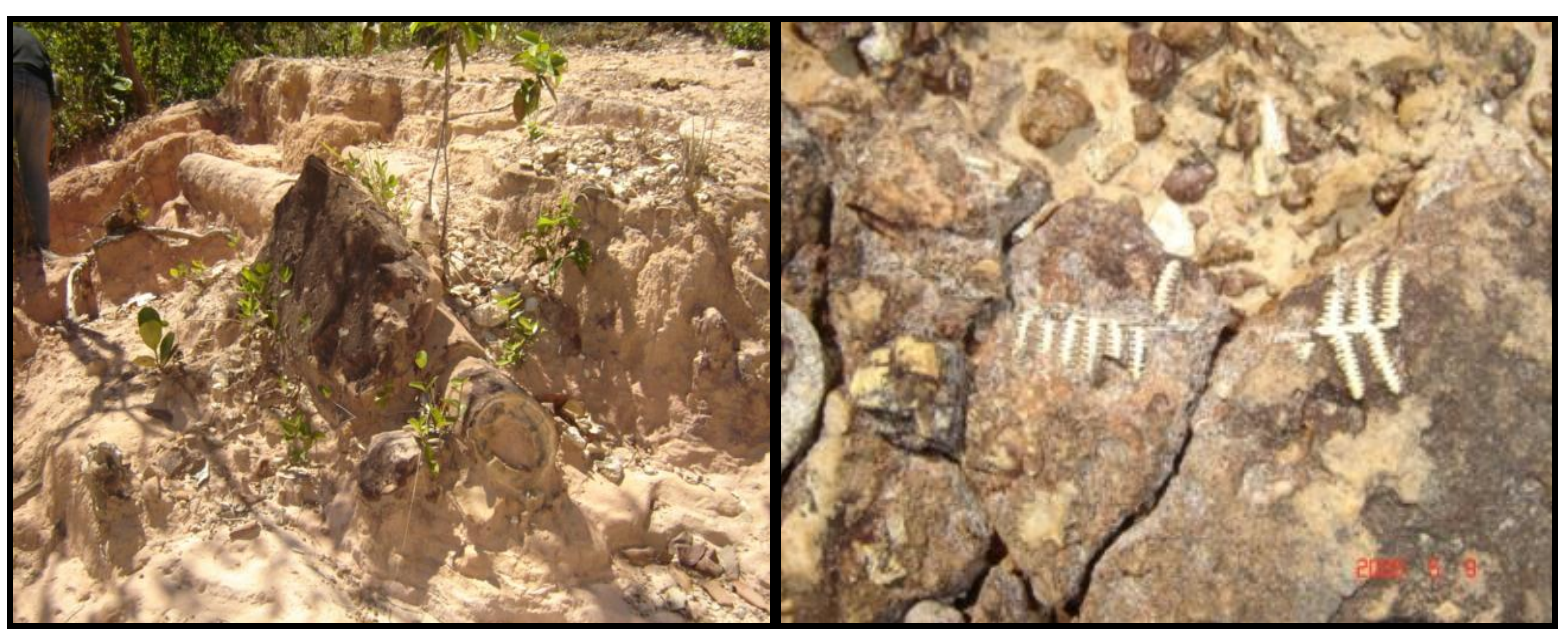

Fonte: Tocantins (2005)

Figura 6: Vista Geral do Monumento das Árvores Fossilizadas

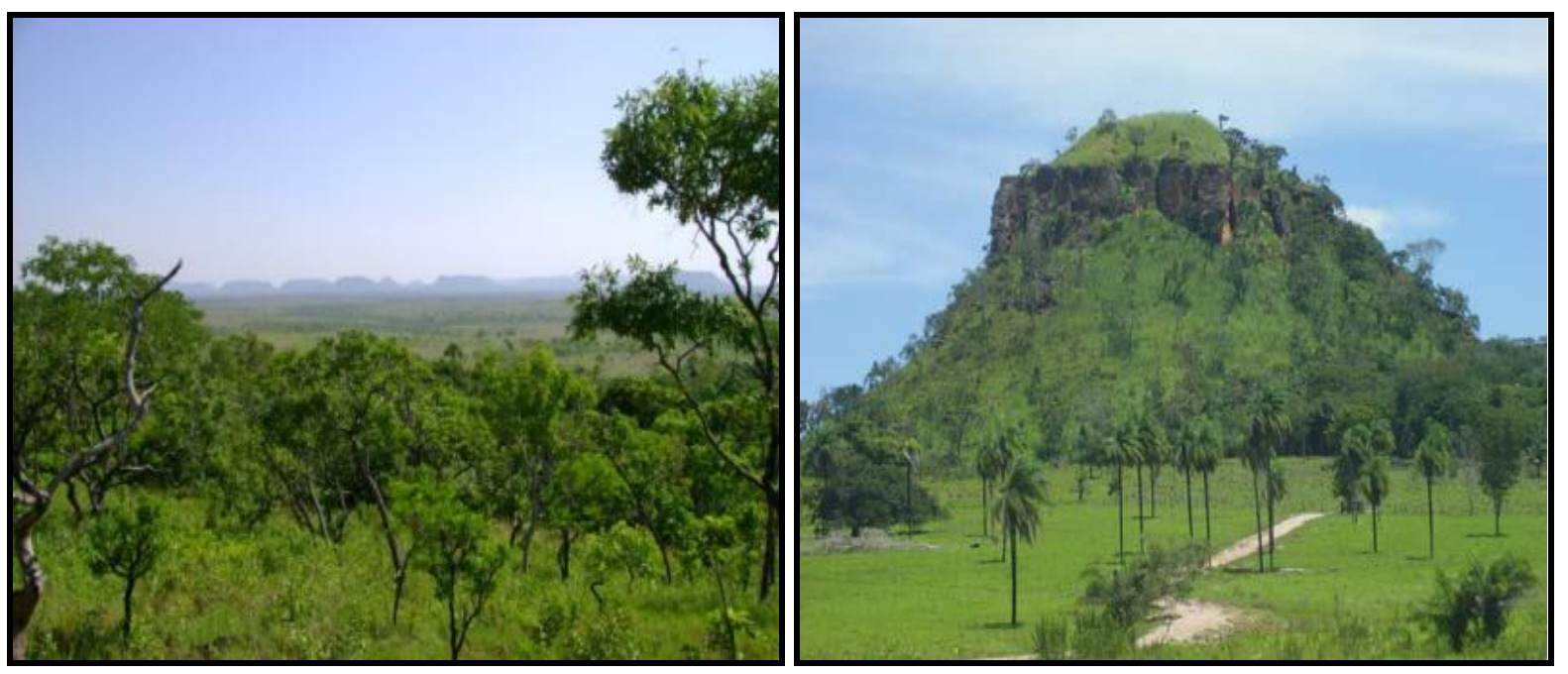

Coordenadas: $07^{\circ} 28^{\prime} 03^{\prime \prime} \mathrm{S} / 48^{\circ} 49^{\prime} 18^{\prime \prime}$ Wgr

Fonte: Tocantins (2005)

Com o devido estudo e locais adequados inúmeros morros podem ser utilizados para o esporte de aventura como trilhas e rapel, desde acompanhados por guias e profissionais desta prática esportiva, porém restritiva para pessoas idosas e crianças devido as distâncias das caminhadas, subidas de relevos íngremes e as temperaturas mais elevadas, principalmente no período da tarde.

$\begin{array}{llllll}\text { Caminhos de Geografia } & \text { Uberlândia - MG } & \text { v. 19, n. } 68 & \text { Dez/2018 } & \text { p. 250-265 } & \text { Página } 261\end{array}$


Com grandes áreas de preservação das matas, o MONAF pode oferecer paradas para breves reconhecimentos da vegetação, já que a flora local possui inúmeras espécies frutíferas endêmicas e medicinais, além da beleza da época de floração no período de agosto a outubro. A observação de pássaros e animais requer locais adequados e aparelhos como o binóculo, evitando a aproximação e o stress dos animais e aves.

Os cursos de água após o período de chuvas possuem volume razoável de água e trechos com velocidade que podem ser adaptados ao esporte de canoagem, vide Figura 7 e na época de estiagem (julho-setembro) podem ser utilizados como áreas de banho e lazer devido à boa qualidade das águas.

As áreas de lazer e canoagem localizam-se na zona de amortecimento do e na região vizinha MONAF, não sendo restritivas pelas normas do plano de manejo para a utilização e com isso aumentando o leque de atividades da área.

Figura 7: Cursos de água na cheia $(A)$ e na estiagem (B)
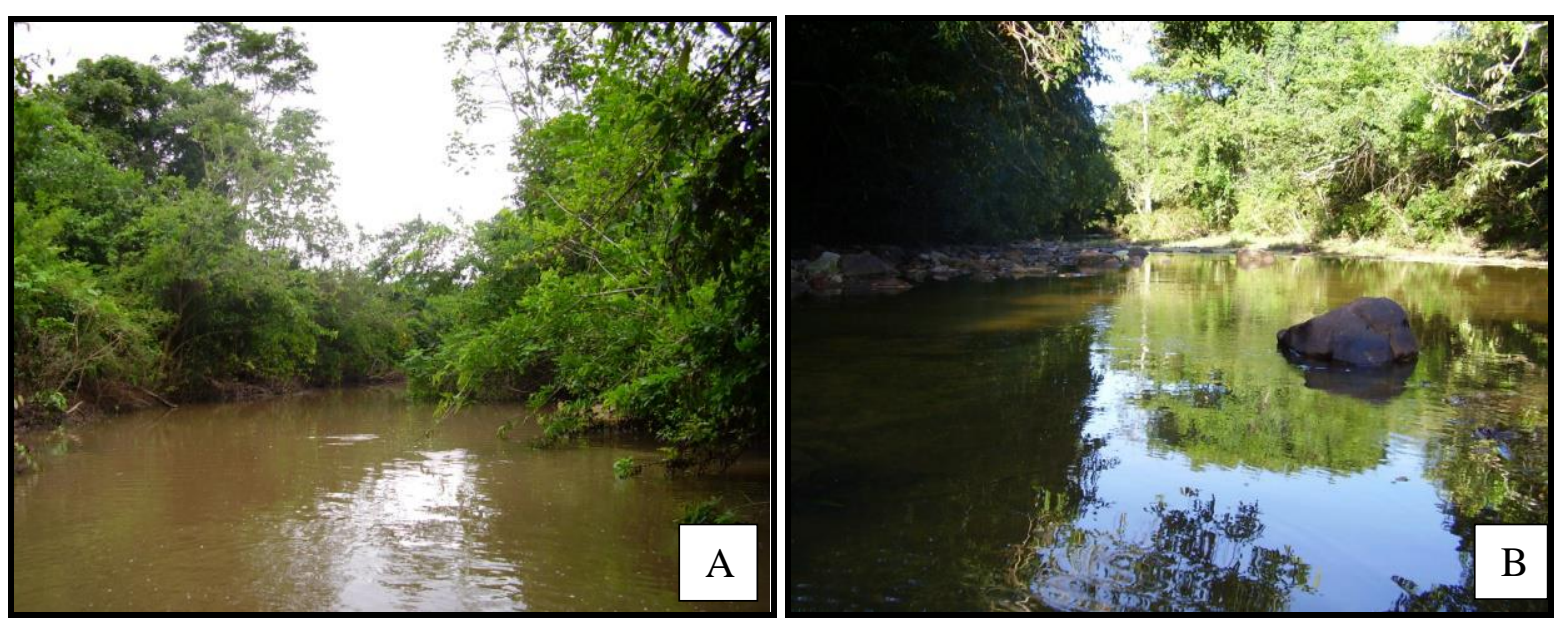

Fonte: Tocantins (2005)

Além dos sítios fósseis, outro fator a ser explorado são os sítios arqueológicos que atestam a presença humana na região apresentando inscrições rupestres, materiais líticos e cavernas que serviram de abrigo as populações pretéritas, vide Figura 8. Devido a fragilidade destes sítios, o número de visitas é limitado para alguns grupos de estudantes e pesquisadores para aumentar a preservação do local. Apesar de identificados e mapeados nenhum estudo aprofundado foi realizado até o presente momento para a geração de informações sobre a importância da presença humana na área, bem como informações que possam ser repassadas aos visitantes.

As inscrições nas rochas possuem a representação de folhas, animais, pessoas, entre outros. Os locais estão em áreas mais isoladas e com um acesso dificultado por alguns pontos com travessia sobre córregos. A capacidade de carga e visitação é mais restrita pelas gravuras estarem em pequenas cavernas, sendo limitado para grupo de cinco pessoas devido ao lento deslocamento entre os rochedos e a pequena área de observação. O local não é indicado para pessoas idosas e crianças.

As rotas devem proporcionar variedade de temas do MONAF, como fósseis, paisagens e gravuras rupestres de modo que o visitante tenha uma holística da evolução da paisagem. 
Figura 8: Inscrições Rupestres em Arenito Eólico

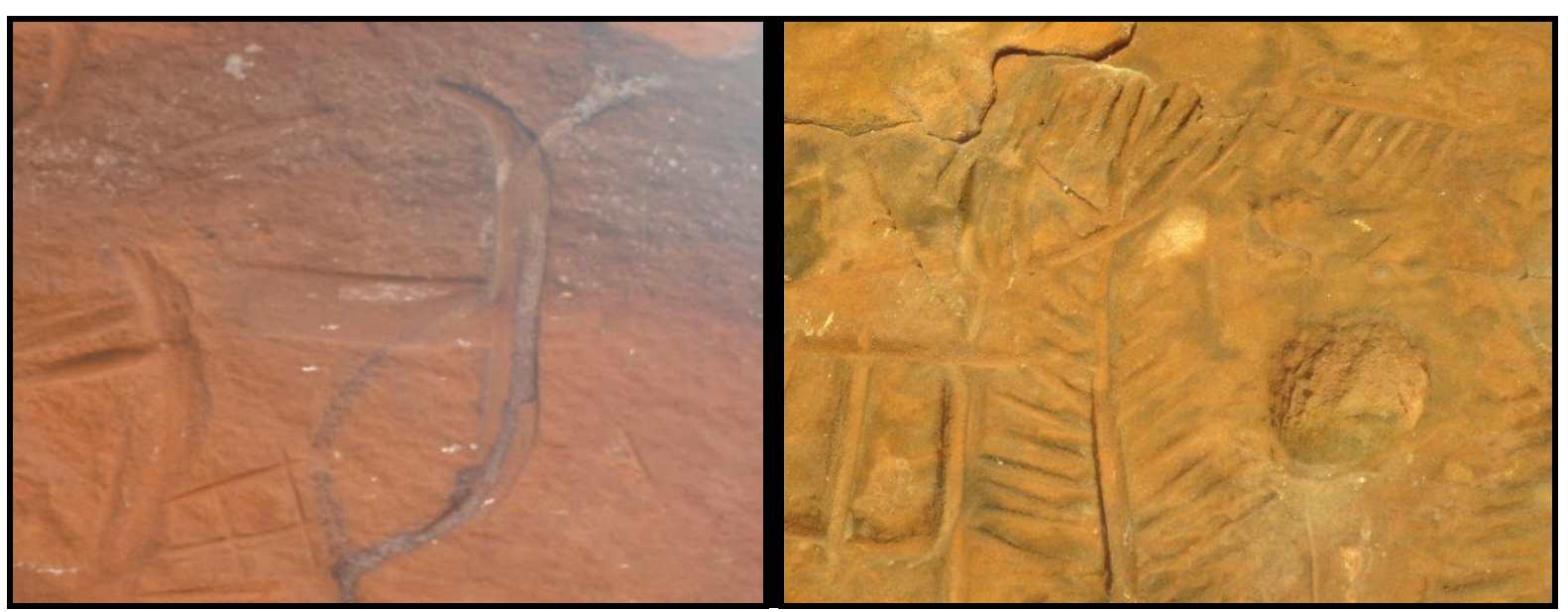

Fonte: Autores (2009)

\section{CONSIDERAÇÕES FINAIS}

O MONAF é de enorme relevância para o estudo dos paleoambientes e paleofloras passadas na região dos Cerrados, mas para maior efetivação da implantação de rotas de turismo e dos trabalhos de conservação do material in situ seriam necessárias algumas medidas como:

- Aumento da fiscalização e ações de conscientização através da educação ambiental.

- Criação de um museu paleontológico na área do Monumento para visitação, preservação e estudo dos fósseis.

- Instalação de trilhas aos sítios fósseis e aos ambientes naturais para visitação pública favorecendo a exploração geoturística no local, aumentando a geração de renda e empregos.

- Trabalhos de conservação do solo no entorno dos sítios fósseis evitando a expansão das erosões e consequentemente danos aos materiais.

- Instalação de passeios e passarelas cercados evitando danos e trânsito aos sítios.

- O MONAF quando de sua instalação realizou um estudo técnico dos recursos ambientais e socioeconômicas da área e o plano de manejo no ano de 2005, porém é necessário a atualização de dados e informações, sendo que o convênio entre UFT e NATURATINS desenvolveu em conjunto várias atividades regulares como disseminação de informações com palestras nas escolas da região, aulas de campo e principalmente estudos em forma de artigos como os de Machado (2012) e Pires et al. (2011), Tavares et al. (2014), dissertações e teses da Universidade Federal do Tocantins (UFT), Universidade de São Paulo (USP), Universidade Estadual Paulista (UNESP) e Universidade Federal do Rio Grande do Sul (UFRGS).

- No corrente ano, os profissionais locados na sede do MONAF no distrito de Bielândia concluíram o estudo das informações para serem colocados nas placas de sinalização das trilhas e no entorno da Unidade de Conservação e que aguarda verba para sua conclusão.

- A implantação da Unidade de Conservação favoreceu a comunidade local na geração de renda como pequenos restaurantes para apoio à visitação, obras como o Museu do NATURATINS no distrito de Bielândia, contratação de moradores para atuar na brigada de incêndio, guias turísticos, entre outros.

- Ampliação dos trabalhos de cooperação do NATURATINS e Universidades.

- Combate ao desmatamento e a prática das queimadas amplamente empregadas na renovação dos pastos.

Grande parte da população local e cidades da região desconhecem a existência deste enorme acervo fóssil na área e deste modo credita pouca importância a conservação e preservação desta Unidade de Conservação para o público e para a ciência. O ambiente natural dos Cerrados em todo território brasileiro vem sendo reduzido drasticamente pelo avanço da fronteira agrícola e a ampliação da urbanização provocando a extinção da fauna e da flora atual e pretérita preservada nos sedimentos.

$\begin{array}{llllll}\text { Caminhos de Geografia } & \text { Uberlândia - MG } & \text { v. 19, n. } 68 & \text { Dez/2018 } & \text { p. 250-265 } & \text { Página } 263\end{array}$




\section{REFERÊNCIAS}

AB'SÁBER, A. N. Problemática da desertificação e da savanização no Brasil Intertropical. Geomorfologia, São Paulo, n. 53, 1977, p. 1-19.

AB' SABER, A. N. Domínios de Natureza do Brasil: Potencialidades Paisagísticas. São Paulo: Ateliê Editorial, 2003.

BERTRAND, G. Paysage et Geographie Physique Globale. Esquisse Méthodologique. In: Caderno de Ciências da Terra. Instituto de Geografia da Universidade de São Paulo, n. 13, 1972.

BRASIL - Departamento Nacional de Produção Mineral. Projeto Radam. Folha SB.22 Araguaína e parte da Folha SC.22 Tocantins. Rio de Janeiro: DNPM, 1974.

BRASIL (Programa Levantamentos Geológicos Básicos do Brasil - PLGB). Carta Geológica Araguaína - Folha SB.22-Z-D, Estados do Tocantins e do Pará. Escala 1:250.000 / Organizado por Vanderlei Antônio de Araújo e Odair Oliatti. - Brasília: CPRM/DIEDIG/DEPAT, 2001.

BRASIL. Ministério do Meio Ambiente. SNUC - Sistema Nacional de Unidades de Conservação da Natureza: Lei no 9.985, de 18 de julho de 2000; Decreto $n^{\circ}$ 4.340, de 22 de agosto de 2002; Decreto № 5.746, de 5 de abril de 2006. Plano Estratégico Nacional de Áreas Protegidas: Decreto oㅜ 5.758, de 13 de abril de 2006. Brasília: MMA, 2011. 76 p.

BRILHA, J. Patrimônio Geológico e Geoconservação: A conservação da natureza na sua vertente geológica. Braga (Portugal), Palimage editores, 2005

KONOLD, W. Dynamism and Change of Cultural Landscape: What can Biosphere reserves accomplish ? In: UNESCO, 2007, p. $18-21$.

MACHADO, C.A. Desmatamentos e queimadas na região norte do Estado do Tocantins. Caminhos de Geografia. v.13, n.43, p.217-229, 2012. Disponível em:

http://www.seer.ufu.br/index.php/caminhosdegeografia/article/view/16609/10528. Acesso em: 23/06/2015.

MENK, J. R. F.; ROSSI, M; BERTOLANI, F. C.; COELHO, M. R.; FERNÁNDEZ, G. Á. V.. Projeto de Gestão Ambiental Integrada da Região do Bico do Papagaio. Zoneamento Ecológico-Econômico. Secretaria do Planejamento e Meio Ambiente (SEPLAN). Diretoria de Zoneamento EcológicoEconômico (DZE). Araguaína. Solos da Folha SB.22-Z-D. Estado do Tocantins. Escala 1:250.000. Org. por Gonzalo Álvaro Vázquez Fernández. 2.ed. Palmas, Seplan/DZE, 2004.

OLIVEIRA, P. E. et all Paleovegetação e Paleoclimas do Quaternário no Brasil. In: SOUZA, C. R. G. et all. (Orgs) Quaternário do Brasil, Ribeirão Preto: Holos, 2005. p. 52 - 74.

PEIXE, R. G. A atividade turística como potencial de desenvolvimento territorial. Estudo de caso: município de Botuverá (SC). In: Anais do VI Seminário de Pesquisa em Turismo do Mercosul: Saberes e fazeres no turismo: Interfaces, julho (2010, Caxias do Sul (RS), 2010, p. 1- 15.

PIRES, E.F.; GUERRA-SOMMER M.; BARDOLA T.; VEECK G.P. Padrões de crescimento em lenhos gimnospérmicos como indicadores paleoclimáticos na Floresta Petrificada do Tocantins Setentrional (Permiano) Bacia do Parnaíba, Tocantins, Brasil. In: MORAES, F. (ed.). Contribuições à Geografia Física do Estado do Tocantins, Palmas, Kelps, p. 113-134; 2011.

RIZZINI, C. T. Tratado de Fitogeografia do Brasil. Rio de Janeiro: Âmbito Cultural, 1997

ROBRAHN-GONZÁLES, E. M. et all Estudos Geológicos e Paleontológicos do Monumento Natural das Árvores Fossilizadas do Estado do Tocantins. Relatório Final - Instituto de Natureza do Tocantins, Magna Engenharia Ltda, 2002.

RUSCHMANN, D. van M.. Turismo e planejamento sustentável. Papirus, Campinas (SP), 1997.

SANTOS, M. E. C. M. ; CARVALHO, M. S. S. Paleontologia das Bacias do Parnaíba, Grajaú e São Luís. Rio de Janeiro, CPRM (Serviço Geológico do Brasil/DIEDIG/DEPAT), 2004.

TAVARES, T.M.V.; ROHN, R.; RÖßLER, R.; NOLL, R. Petrified Marattiales pinnae from the Lower Permiano of North-Western Gondwana (Parnaíba Basin, Brazil). Review of Paleobotany and Palynology. v.201, p.12-28, 2014. https://doi.org/10.1016/j.revpalbo.2013.09.002 
TOCANTINS (ESTADO) Secretaria do Planejamento e Meio Ambiente. Diagnóstico dos Recursos Hídricos das Bacias dos Rios Lontra e Corda, na Região do Bico do Papagaio - TO. Palmas: SEPLAN, 2001.

TOCANTINS (ESTADO) Plano de Manejo do Parque Estadual Monumento Natural das Árvores Fossilizadas. Consórcio OIKOS- MRS Estudos Ambientais, 2005.

TOCANTINS (ESTADO) Secretaria do Planejamento e Meio Ambiente. Projeto de Gestão Ambiental Integrada da Região do Bico do Papagaio. Zoneamento Ecológico-Econômico. Análise Ambiental e Socioeconômica: Norte do Estado do Tocantins. Palmas, 2004.

VIEIRA, A.; CUNHA, L. A. Importância dos Elementos Geomorfológicos na Valorização da Paisagem: Exemplos em Morfologias Cársicas e Graníticas. In: Acta do IX Colóquio Ibérico de Geografia, Huelva, 2002.

Recebido em: 13/12/2017

Aceito para publicação em: 19/10/2018 